\title{
Identification of Heat Transfer Coefficients and Simulation of Quenching Distortions on Disk Probe
}

\author{
Hideo Kanamori ${ }^{1, *}$ and Dong-Ying $\mathrm{Ju}^{2, *}$ \\ ${ }^{1}$ Advanced Science Institute, Saitama Institute of Technology, Fukaya 369-0293, Japan \\ ${ }^{2}$ Saitama Institute of Technology, Fukaya 369-0293, Japan
}

\begin{abstract}
Oil quenching is an efficient heat treatment cooling method which can obtain a large cooling capacity by utilizing the boiling phenomenon However, when the vapor film remains, the cooling speed is reduced only in the part, and the uneven cooling can cause heat treatment distortion, which is the biggest problem in the heat treatment process. In this paper, a quenching experiment was conducted by immersing a horizontal stainless steel disk specimen in quenching oil. Thermocouples which just located below the surface accurately measure the cooling curves of the top and bottom surfaces of the specimen.

In this study, the temperature-dependent heat transfer coefficients were identified from the cooling curves by the inverse method using the analytical solution derived from the Fourier heat conduction equation of the disk.

In addition, a visualization experiment was conducted, in which a laser beam sheet was put into the oil tank of the equipment, and the boiling phenomenon, the formation of a vapor film, and the film boiling phenomenon were observed using a high-speed video camera.

Furthermore, in order to verify the correctness of the heat transfer coefficient obtained by the inverse solution method, the heat transfer coefficient was substituted into the heat treatment simulation software "COSMAP" and the quenching distortion calculation was performed by executing the quenching simulation calculation of the disk. It was proved that the prediction accuracy was improved.

[doi:10.2320/matertrans.H-M2020810]
\end{abstract}

(Received November 29, 2019; Accepted February 18, 2020; Published April 25, 2020)

Keywords: cooling curves, boiling, heat transfer coefficient, inverse method, heat conduction equation, simulation, distortion

\section{Introduction}

In the oil quenching process, the strength and wear resistance of parts are improved by putting steel parts heated to a temperature 800 to $900^{\circ} \mathrm{C}$ into oil, whose volume is 10 times or more comparing to steel parts and fixture. The boiling point range of oil shows at 200 to $400^{\circ} \mathrm{C}$. Then, in such a process, with changing the cooling characterization, ${ }^{1-3)}$ the liquid phase transformed to vapor phase on the solid surface, which brought some influences such as stress and strain, phase transformation, heat shrinkage, causing that some interaction each other above them occurred in the steel materials. $^{4-7)}$

For such a complex system, it is very difficult to predict quenching problem (e.g. distortion) of steel component. In recent years, to solve these problems, computer aided engineering (CAE) heat treatment simulations have been used to develop simulation techniques for phase transformation, temperature change, and coupled stress and strain analysis. Especially, since the Intelligent Manufacturing System (IMS) international joint research project as IMSVHT started in 2003, heat treatment simulation code COSMAP $^{5-7)}$ was developed, and heat treatment simulation of automobile parts such as gears was also performed. ${ }^{8-11)}$

Considering the phenomenon of oil quenching, in the initial stage of cooling, the surface of the solid is covered with a vapor film, reaches the nucleate boiling state after passing the characteristic temperature at which the vapor film collapses, and finally reaches the convection stage. ${ }^{12)}$ On the other hand, in the nucleate boiling stage, in addition to the latent heat of liquefaction, self-stirring occurs due to the collapse and disappearance of the vapor bubbles, so that a

*Corresponding authors, E-mail: dyju@sit.ac.jp, kanamori@sit.ac.jp, h-oking@pc4.so-net.ne.jp greater cooling capacity can be obtained. In the convection stage below the boiling point range, there is a region where the cooling speed can be controlled by a predetermined flow rate. Therefore, oil cooling is a useful method with various means. However, the vapor film impedes the cooling, and the timing of the collapse of the vapor film at each location is also different. This is the cause of heat treatment distortion, it is difficult to control quality of parts, and the production cost increases, which is an important incidental issue at the parts production site.

Such behavior of the coolant affects the metal surface, resulting in a bottom surface temperature. When measuring the temperature at the center of the sample, there is a delay from the actual change in surface temperature, and it is difficult to accurately read the change in surface temperature. $^{12,13)}$ On the other side, the method of measuring the surface temperature of the side surface of a silver cylinder specified in JIS K 2242 method $\mathrm{A}^{14)}$ faithfully shows the temperature change of the surface of the cooling liquid cooled by the vapor film and nucleate boiling and the phenomenon of the heat convection stage. However, there is a problem that the characteristic temperature at which the vapor film collapses is measured 80 to $100^{\circ} \mathrm{C}$, which is lower than that of steel. Thus, it is known that the characteristic temperature becomes lower by the influence of the surface modification. ${ }^{15)}$ In addition, it is difficult to set the part where the vapor film stagnates and the part where the vapor film collapses.

In this paper, quenching was performed by placing a disk specimen of JIS SUS304 material that does not undergo phase transformation due to quenching horizontally in quenching oil. From the side of the disk to the place near the center of the top surface and the bottom surface, two small holes were drilled for inserting of the thermocouple. Using this method, the temperature and cooling curves at 
two points on the bottom and top of the disk are measured. In addition, visualization experiments using a laser beam sheet and a high-speed video camera are performed to observe the boiling phenomenon, the formation of a vapor film, and the film boiling phenomenon. As a result, after starting the cooling immediately, the first boiling stage was observed.

This first boiling stage occurs immediately before a vapor film is formed on both the top and bottom surfaces, Subsequently, in the film boiling stage, the cooling curve reflecting the thermal states of the top and bottom surfaces was obtained. It was observed to represent a different cooling process.

For the identification of the heat transfer coefficient, the inside of the disk was assumed to be homogeneous and isotropic, when using the heat conduction equation applied to the solid. Boundary conditions were assumed to have heat dissipation based on obeying Newton's cooling low of outside the top and bottom boundaries. In addition, the cooling curve is divided into $60 \sim 100$ step intervals, and the analytical solutions for the heat conduction equation, initial conditions, and boundary conditions are set individually, and the cooling curves for the temperature-dependent top and bottom surfaces are converted into analytical solutions. The heat transfer coefficients of $h_{1}(T)$ and $h_{2}(T)$ on the top and bottom surfaces are identified by inverse analysis. The heat transfer coefficients $h_{1}(T)$ and $h_{2}(T)$ obtained by this method are used for heat treatment simulation, and high-precision heat treatment simulation and quenching strain analysis are performed.

\section{Method of Identifying Heat Transfer Coefficient}

\subsection{Measurement of cooling curves}

\subsubsection{Test specimen}

The chemical composition of JIS SUS304 steel used for disk specimen is shown in Table 1. The disk had a diameter of $35.0 \mathrm{~mm}$ and a thickness of $10.0 \mathrm{~mm}$ and the jig had an inner diameter of $35.2 \mathrm{~mm}$ and outer diameter of $49.0 \mathrm{~mm}$, as shown at the top of Fig. 1(a). Fixing was done with three sets of screws, each with a contact area of about $1 \mathrm{~mm}^{2}$ or less on the ring side face. Therefore, a gap of $0.1 \mathrm{~mm}$ was formed on the outside of the disk and inside face of the jig to form a heat insulating wall.

Oblique holes were made at an angle of $6.74^{\circ}$ with respect to the horizontal direction from the outside face of the ring toward the immediate center of both the upper and bottom surfaces of the test specimen. The element wires (diameter was $0.2 \mathrm{~mm}$ ) were drawn from a $\mathrm{K}$ type sheathed thermocouple $(1.0 \mathrm{~mm}$ outer diameter) was welded (tip diameter was about $0.3 \mathrm{~mm}$ ) at $0.1 \mathrm{~mm}$ or less below the center both the top and bottom surfaces to fix the thermocouple contact with silver paste, as shown at the bottom of Fig. 1(a). To measure the temperature of the center of the disc specimen, the $\mathrm{K}$ type sheathed thermocouple was

Table 1 Chemical compositions \% of SUS304 steel.

\begin{tabular}{|l|l|l|l|l|l|l|l|}
\hline $\mathbf{C}$ & $\mathbf{S i}$ & $\mathbf{M n}$ & $\mathbf{P}$ & $\mathbf{S}$ & $\mathbf{N i}$ & $\mathbf{C r}$ & $\mathbf{C u}$ \\
\hline 0.04 & 0.49 & 1.38 & 0.39 & 0.22 & 8.06 & 18.05 & 0.19 \\
\hline
\end{tabular}

(a)

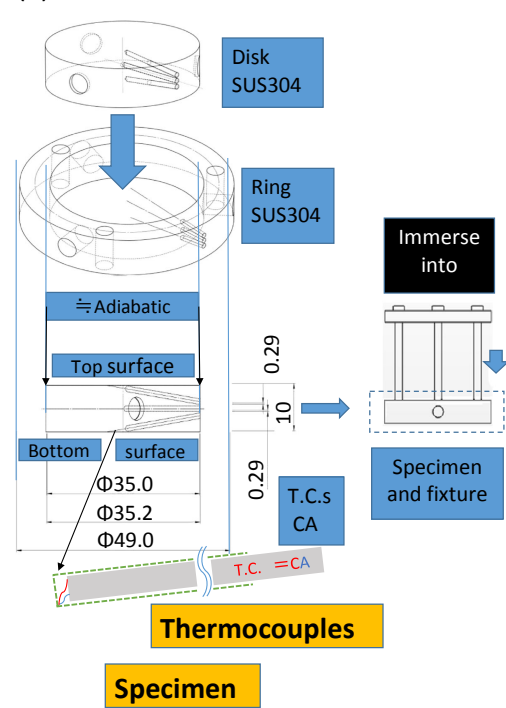

(b)

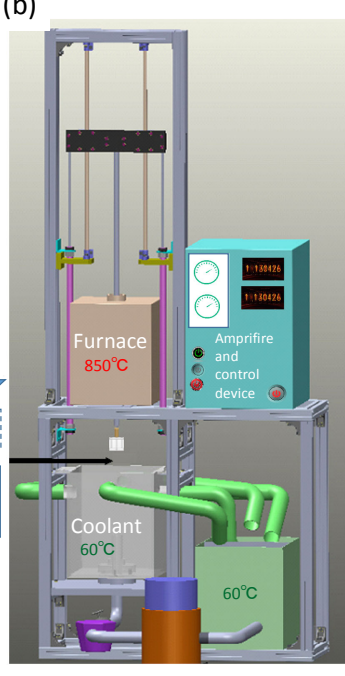

Apparatus

Fig. 1 Structure and shape of disc probe left side, Schematic diagram of experimental equipment in right side.

Table 2 Property of coolant (Commercial oil: Daphne Bright Quench).

\begin{tabular}{|c|c|c|c|c|}
\hline $\begin{array}{c}\text { Temperature, } \\
{ }^{\circ} \mathbf{C}\end{array}$ & $\begin{array}{c}\text { Density, } \\
\mathbf{k g} / \mathbf{m}^{\mathbf{3}}\end{array}$ & $\begin{array}{c}\text { Kinematic } \\
\text { viscosity, } \\
\mathbf{m m}^{\mathbf{2}} / \mathbf{s}\end{array}$ & $\begin{array}{c}\text { Thermal } \\
\text { conductivity, } \\
\mathbf{W} /(\mathbf{m} \cdot \mathbf{K})\end{array}$ & $\begin{array}{c}\text { Specific Heat, } \\
\mathbf{J} /(\mathbf{k g} \cdot \mathbf{K})\end{array}$ \\
\hline 60 & 834.9 & 14.94 & 0.1315 & 2.03 \\
\hline 70 & 828.7 & 11.20 & 0.1307 & 2.07 \\
\hline 80 & 822.5 & 8.667 & 0.1300 & 2.11 \\
\hline
\end{tabular}

inserted among the horizontal direction in length of $24.5 \mathrm{~mm}$ from center position (at a distance of $5 \mathrm{~mm}$ from top or bottom surfaces) of side.

\subsubsection{Experimental equipment and sample coolant}

For the measurement, an experiment was conducted using a cooling tester manufactured by Nissho Engineering Co. Ltd.

As a sample coolant, commercially available cold quenching oil "Daphne Bright Quench" was used. Table 2 shows properties of this oil that was used temperature $T_{\infty}=$ $60^{\circ} \mathrm{C}$.

\subsubsection{Measurement of cooling curves}

The specimen and ring holder were uniformly heated to $850 \pm 5^{\circ} \mathrm{C}$ in a furnace, as shown at the top of Fig. 1(b), and immersed into the sample coolant at a liquid temperature of $T_{\infty}=60^{\circ} \mathrm{C}$, at the lower part of Fig. 1(b). The specimen was immersed into the coolant oil, it was taken $0.28 \mathrm{~s}$ during this time from furnace to oil surface. To obtain curves reflecting the relations about the surface temperature $(T)$ and the elapsed time $(t)$, the temperatures of the top, bottom and inter surfaces of the disk probe were measured by thermocouples. And these signals were amplified and converted by the operational amplifier/AD converter (TUSB-STC2Z) made by the TURTLE Industry Co., Ltd.

\subsection{Visualization of phenomenon}

To observe the cooling behavior, a $4 \mathrm{~K}$ camera "GoPro HERO 6 Black CHDHX-601-FW" manufactured by ZEN International Corporation and an Nd: YVO 4 laser SOC were used and 240FPS video shooting was done. 


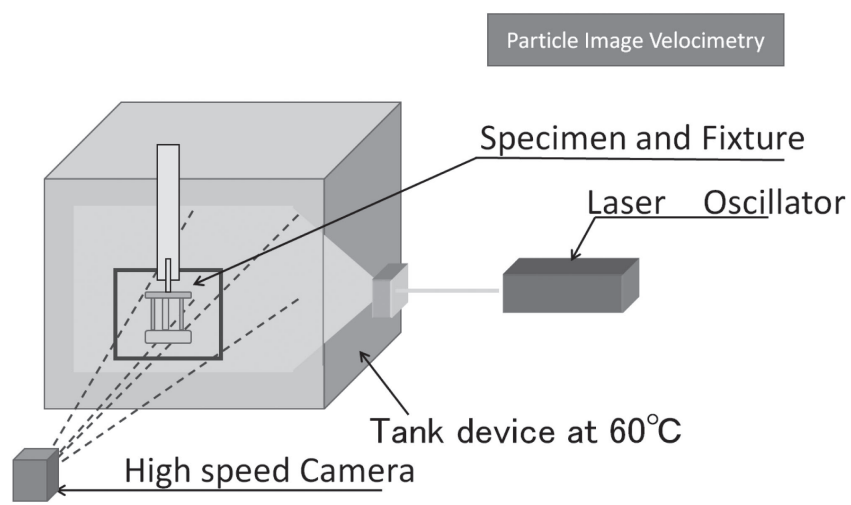

Fig. 2 Schematic diagram of visualization device.

The laser beam was emitted using a transformed crystal with a wavelength of $532 \mathrm{~nm}$ which the schematic of the experimental system is shown in Fig. 2. To observe the presence of residual vapor film under the bottom surface, the laser beam was set to $-7.2^{\circ}$ with respect to surface of specimen bottom.

\subsection{Theory of inverse analysis}

\subsubsection{Heat conduction equation}

\subsubsection{The heat flux vector and Fourier's law}

For a homogeneous, isotropic solid (i.e., material in which thermal conductivity is independent of direction), the Fourier's law as

$$
\vec{q}(\vec{r}, t)=-k \nabla T(\vec{r}, t)
$$

$\begin{array}{ll}\vec{q}(\vec{r}, t): \text { heat flux vecter } & \text { units }(S I) \\ k: \text { thermal conductivity } & : W / m^{2}=(\mathrm{J} / \mathrm{s}) / \mathrm{m}^{2} \\ T(\vec{r}, t): \text { Temperature distribution } & :{ }^{\circ} \mathrm{C} / \mathrm{m} \\ \nabla T: \text { Temperature gradient } & : W /\left(m \cdot{ }^{\circ} \mathrm{C}\right) \\ t: \text { time } & : s\end{array}$

Here, the temperature gradient $\nabla T(\vec{r}, t)$ is a vector normal to the isothermal surface, the heat flux vecter $\overrightarrow{\boldsymbol{q}}(\overrightarrow{\boldsymbol{r}}, t)$ represents heat flow per unit time, per unit area of the isothermal surface in direction of the decreasing temperature, and $k$ is called the thermal conductivity of the material which is a positive, scalar quantity.

In the rectangular coordinate system, eq. (1) was written as

$$
\overrightarrow{\boldsymbol{q}}(x, y, z, t)=-\overrightarrow{\boldsymbol{i}} k \frac{\partial T}{\partial x}-\overrightarrow{\boldsymbol{j}} k \frac{\partial T}{\partial y}-\overrightarrow{\boldsymbol{k}} k \frac{\partial T}{\partial z}
$$

Where $\overrightarrow{\boldsymbol{i}}, \overrightarrow{\boldsymbol{j}}$, and $\overrightarrow{\boldsymbol{k}}$ are the unit direction vectors along the $x, y$, and $z$ directions, respectively. Thus, the three components of the heat flux vector in the $x, y$, and $z$ directions, respectively, represented by

$$
q_{x}=-k \frac{\partial T}{\partial x}, \quad q_{y}=-k \frac{\partial T}{\partial y}, \quad q_{z}=-k \frac{\partial T}{\partial z}
$$

Clearly, the heat flow rate for a given temperature gradient is directly proportional to the thermal conductivity $k$ of material. ${ }^{15}$ )

\subsubsection{The differential equation of heat conduction}

Deriving the differential equation of heat conduction for a stationary, homogeneous, isotropic solid without heat generation inside the disk, considering the energy balance

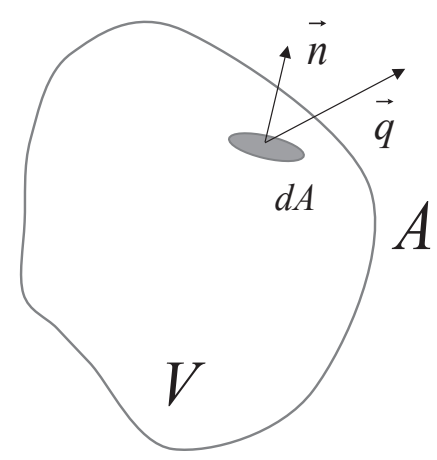

Fig. 3 Infinitesimal area, $d A$ and heat flux vector $\vec{q}$ in small control volume V.

relation for a small control volume, illustrated in Fig. 3, stated as

$$
\begin{aligned}
& \left(\begin{array}{c}
\text { Rate of heat entering through the } \\
\text { bounding surfaces of } V
\end{array}\right) \\
& =\left(\begin{array}{c}
\text { Rate of storage of } \\
\text { energy in } V
\end{array}\right)
\end{aligned}
$$

In thermal energy, evaluated as

$$
\begin{gathered}
\left(\begin{array}{c}
\text { Rate of heat entering through the } \\
\text { bounding surfaces of } V
\end{array}\right) \\
=-\int_{A} \overrightarrow{\boldsymbol{q}} \cdot \overrightarrow{\boldsymbol{n}} d A=-\int_{V} \nabla \cdot \overrightarrow{\boldsymbol{q}} d v
\end{gathered}
$$

Where, $A$ is the surface area of the volume element $V, \vec{n}$ is outword-down normal unit vector to the surface element $d A$; here, the minus sign means direction, heat flux vecter $\overrightarrow{\boldsymbol{q}}(\overrightarrow{\boldsymbol{r}}, t)$ is pointing out of the substance.

Using divergence theorem to convert the surface integral to volume integral, which were shown in eq. (5), the rate of energy storage is expressed as

$$
\left(\begin{array}{c}
\text { Rate of storage of energy } \\
\text { in } V
\end{array}\right)=\int_{V} \rho C_{P} \frac{\partial T(\overrightarrow{\boldsymbol{r}}, t)}{\partial t} d v
$$

Therefore, from eqs. (4), (5) and (6) is written as

$$
\begin{gathered}
-\int_{V} \nabla \overrightarrow{\boldsymbol{q}}(\overrightarrow{\boldsymbol{r}}, t) d v-\int_{V} \rho C_{P} \frac{\partial T(\overrightarrow{\boldsymbol{r}}, t)}{\partial t} d v=0 \\
\therefore \int_{V}\left[-\nabla \overrightarrow{\boldsymbol{q}}(\overrightarrow{\boldsymbol{r}}, t)-\rho C_{P} \frac{\partial T(\overrightarrow{\boldsymbol{r}}, t)}{\partial t}\right] d v=0
\end{gathered}
$$

Equation (8) is derived for an arbitrary so small-volume element $V$ within the solid, as to remove the integral,

$$
\therefore-\nabla \overrightarrow{\boldsymbol{q}}(\overrightarrow{\boldsymbol{r}}, t)-\rho C_{P} \frac{\partial T(\overrightarrow{\boldsymbol{r}}, t)}{\partial t}=0
$$

From Fourier's low (1), and eq. (9) as

$$
\begin{gathered}
\nabla^{2} k T(\overrightarrow{\boldsymbol{r}}, t)-\rho C_{P} \frac{\partial T(\overrightarrow{\boldsymbol{r}}, t)}{\partial t}=0 \\
\nabla^{2} T(\overrightarrow{\boldsymbol{r}}, t)=\frac{1}{\alpha} \frac{\partial T(\overrightarrow{\boldsymbol{r}}, t)}{\partial t}
\end{gathered}
$$

Where,

$$
\alpha=\frac{k}{\rho C_{P}}=\text { thermal diffusivity }
$$

$\rho$ is density and $C_{P}$ is isobaric specific heat. ${ }^{14)}$ 


\subsubsection{One-dimensional (1D) heat conduction equation}

Since it is thermally insulated by a $0.1-\mathrm{mm}$ gap between the side surface of the disk and jig, cooling from the side surface is considered negligible, an infinite plate disk having parallel surfaces is assumed and a 1D equation is used.

Therefore, in the cooling process using the oil, the initial temperature functions as $F(x)$ for the top and bottom surfaces of the disk with thickness $L$ were set, and heat transfer coefficient about the two surfaces were calculated. The formulation of $1 D$ equation, from (11) and (3), as

$$
\frac{\partial^{2} T(x, t)}{\partial x^{2}}=\frac{1}{\alpha} \frac{\partial T(x, t)}{\partial t}, \quad \text { in } \quad 0<x<L, t>0
$$

Next, to reduce calculation errors in the case of an attenuation curve in which a number close to 0 appears, the following dimensionless processing was carried out.

$$
x^{*} \equiv \frac{x}{L}, \quad t^{*} \equiv \frac{\alpha t}{L^{2}}, \quad T^{*} \equiv \frac{T-T_{\infty}}{T_{0}-T_{\infty}}
$$

where $\alpha$ is thermal diffusivity, $T_{0}$ is cooling start temperature when the disk is immersed into coolant, and $T_{\infty}$ is temperature of the coolant, According to the eq. (14), the (13) was calculated to the (15).

$$
\frac{\partial^{2} T^{*}\left(x^{*}, t^{*}\right)}{\partial x^{* 2}}=\frac{\partial T^{*}\left(x^{*}, t^{*}\right)}{\partial t^{*}} \quad 0 \leq x^{*} \leq 1, \quad 0 \leq t^{*}
$$

To obtain the heat transfer coefficient depending on temperature, the conditions for obtaining the analytical solution of eq. (15) were set as follows. First, to obtain the solution of eq. (15) at every time interval $T^{*}{ }_{q-1} \leq T^{*} \leq T_{q}^{*}$, the initial condition at $T^{*}{ }_{q-1}$ is expressed as

$$
T\left(x^{*}, t^{*}{ }_{q-1}\right)=F\left(x^{*}\right)
$$

If the heat transfer coefficients of the coolant on the top and bottom surfaces of the disk are $h_{1}$ and $h_{2}$, the boundary conditions are expressed as

$$
\begin{aligned}
-\frac{\partial T^{*}}{\partial x^{*}}+h_{1} \frac{L T^{*}}{k_{1}} & =0 \quad \text { at } \quad x^{*}=0, \quad \tau_{q}^{*}>0 \\
\frac{\partial T^{*}}{\partial x^{*}}+h_{2} \frac{L T^{*}}{k} & =0 \quad \text { at } \quad x^{*}=1, \quad \tau_{q}^{*}>0
\end{aligned}
$$

with respect to the thickness direction of the disk, where,

$$
\tau^{*}{ }_{q} \equiv t^{*}{ }_{q}-t^{*}{ }_{q-1}
$$

\subsubsection{The solution of the heat conduction equation}

When setting boundary condition eq. (17a) and (17b) including $h_{1}$ and $h_{2}$ and temperature distribution $F\left(x^{*}\right)$ for each time interval $\tau^{*}{ }_{q}$ as initial conditions of eq. (16), the solution of eq. (15) is expressed as,

$$
\begin{aligned}
T^{*}\left(x^{*}, t\right) & =\sum_{m=1}^{\infty} \exp \left(-\beta_{m}^{* 2} \tau_{q_{i}}{ }^{*}\right) \frac{1}{N^{*}\left(\beta_{m}^{*}\right)} \cdot R \\
R & =X^{*}\left(\beta_{m}^{*}, x^{*}\right) \int_{0}^{1} X^{*}\left(\beta_{m}^{*}, x^{*}\right) F\left(x^{*}\right) d x^{*}
\end{aligned}
$$

The analytical solution of eq. (15) related to heat transfer coefficient $h_{1}$ and $h_{2}$ are as follows:

$$
X_{m}{ }^{*}\left(\beta_{m}{ }^{*}, x^{*}\right)=\beta_{m}{ }^{*} \cos \beta_{m}{ }^{*} x^{*}+H_{1} L \sin \beta_{m}{ }^{*} x^{*}
$$

The eigen function

$$
\tan \beta_{m}{ }^{*}=\frac{\beta_{m}{ }^{*} L\left(H_{1}+H_{2}\right)}{\beta_{m}{ }^{* 2}-H_{1} H_{2} L^{2}}
$$

is the eigen value and norm $N^{*}\left(\beta_{m}^{*}\right)$ is defined as

$$
N^{*}\left(\beta_{m}^{*}\right)=\int_{0}^{1}\left[X^{*}\left(\beta_{m}^{*}, x^{*}\right)\right]^{2} d x^{*}
$$

From eqs. (20), (21) and (22) as

$$
\begin{aligned}
& N^{*}\left(\beta^{*}{ }_{m}\right)=\frac{1}{2}\left(\beta^{*}{ }^{2}+H_{1}{ }^{2} L^{2}\right) \\
& +\frac{L\left(H_{1}+H_{2}\right)\left(\beta^{*}{ }_{m}^{2}+H_{1} H_{2} L^{2}\right)}{2\left(\beta^{*}{ }_{m}{ }^{2}+H_{2}{ }^{2} L^{2}\right)}
\end{aligned}
$$

Where,

$$
H_{1} \equiv \frac{h_{1}}{k_{1}}, \quad H_{2} \equiv \frac{h_{2}}{k_{2}}
$$

Here, $\alpha=k / c_{p} \rho$ is thermal diffusivity $\left[\mathrm{m}^{2} / \mathrm{s}\right], k$ is heat conductivity $[\mathrm{W} / \mathrm{m} \cdot \mathrm{K}], \quad c_{p}$ is isobaric specific heat $[\mathrm{J} / \mathrm{kg} \cdot \mathrm{K}], \quad \rho$ is density $\left[\mathrm{kg} / \mathrm{m}^{3}\right], h_{1}$ is the heat transfer coefficient of the top surface $\left[\mathrm{W} / \mathrm{m}^{2} \cdot \mathrm{K}\right]$, and $h_{2}$ is the heat transfer coefficient of the bottom surface $\left[\mathrm{W} / \mathrm{m}^{2} \cdot \mathrm{K}\right]$.

Through this procedure, appropriate $h_{1}$ and $h_{2}$ that satisfy eq. (19) in a certain temperature range were identified and substituted into eqs. (20), (21), and (23). The calculated temperature distribution was used as the initial condition of eq. (16) for the next time interval, and the calculation can be continued.

Therefore, the heat transfer coefficients corresponding to all temperatures in the cooling process were identified.

\subsubsection{Identification of heat transfer coefficient}

The heat transfer coefficient curves $h_{1}(T)$ and $h_{2}(T)$ corresponding to the respective temperatures in the cooling process were obtained from the following procedure and as shown in Fig. 4.

The temperature of top and bottom surface was set by the time step interval decreasing up to a certain value. Namely, the temperature interval was set at $1 \sim 3^{\circ} \mathrm{C}$ up to $500^{\circ} \mathrm{C}$, and since $500^{\circ} \mathrm{C}$, the temperature interval was set at $6 \sim 12^{\circ} \mathrm{C}$. Also the identified $H_{1}$ and $H_{2}$ (in before time step interval) were assigned into the (21). The true value of eigen value of $\beta_{m}{ }^{*}$ was obtained repeatedly calculated amplitude by the decayed pendulum method until below $\delta_{\beta}$ in (21) [Step 1]. Then, the calculated $\beta_{m}{ }^{*}$ was assigned into (20) and (19), to calculate the surface temperature $\left(T_{1 \text { cal }}{ }^{*}\right)$. Similarly, the $T_{1 \text { cal }}$ * was repeatedly calculated by the decayed pendulum method, for measured temperature, $T_{\text {mea }}{ }^{*}$ below the tolerance $\left(T_{1 \text { mea }}{ }^{*}-T_{1 \text { cal }}{ }^{*}\right) \leq \delta T$. At this time, if the $T_{1 \text { mea }}{ }^{*}-T_{1 \text { cal }}{ }^{*} \geq \delta_{\beta}$, the $H_{1}$ will be calculated again in the [Step 1] to obtain the $\beta_{m}{ }^{*}$ satisfying the (21) [Step 2]. After the calculating of $H_{1}$, the $H_{2}$ of bottom surface will be calculated repeatedly, similar to the calculated method of $H_{1}$ [Step 3]. After the calculating of $H_{2}$, the $H_{1}$ will be calculated again, with the changing of $H_{2}$ [Step 4]. In [Step 5], the $H_{1}$ and $H_{2}$ were calculated repeatedly, when the $T_{1 \text { mea }}{ }^{*}-$ $T_{1 \text { cal }}{ }^{*} \leq \delta_{T}$ and $T_{2 \text { mea }}{ }^{*}-T_{2 \text { cal }}{ }^{*} \leq \delta_{\mathrm{T}}$ established. Thereinto, the $T_{1 \text { mea }}$ and $T_{1 \text { cal }}$ were the temperature of top surface, and the $T_{2 m e a}$ and $T_{2 c a l}$ were the temperature of bottom surface. As a result, the identification of heat transfer coefficient was completed. 


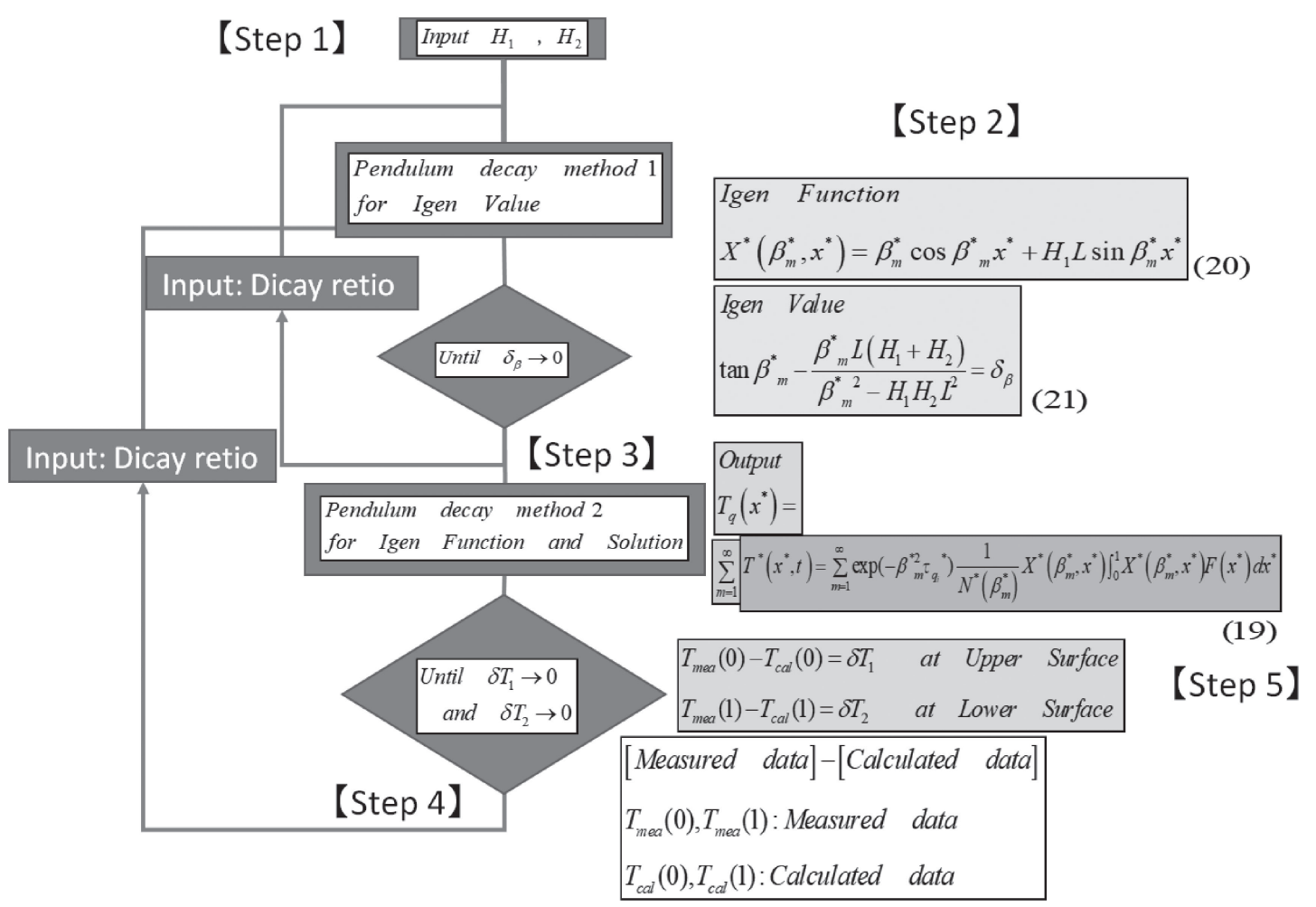

Fig. 4 The procedure of identification of heat transfer coefficients from flat plate cooling curves by inverse method.
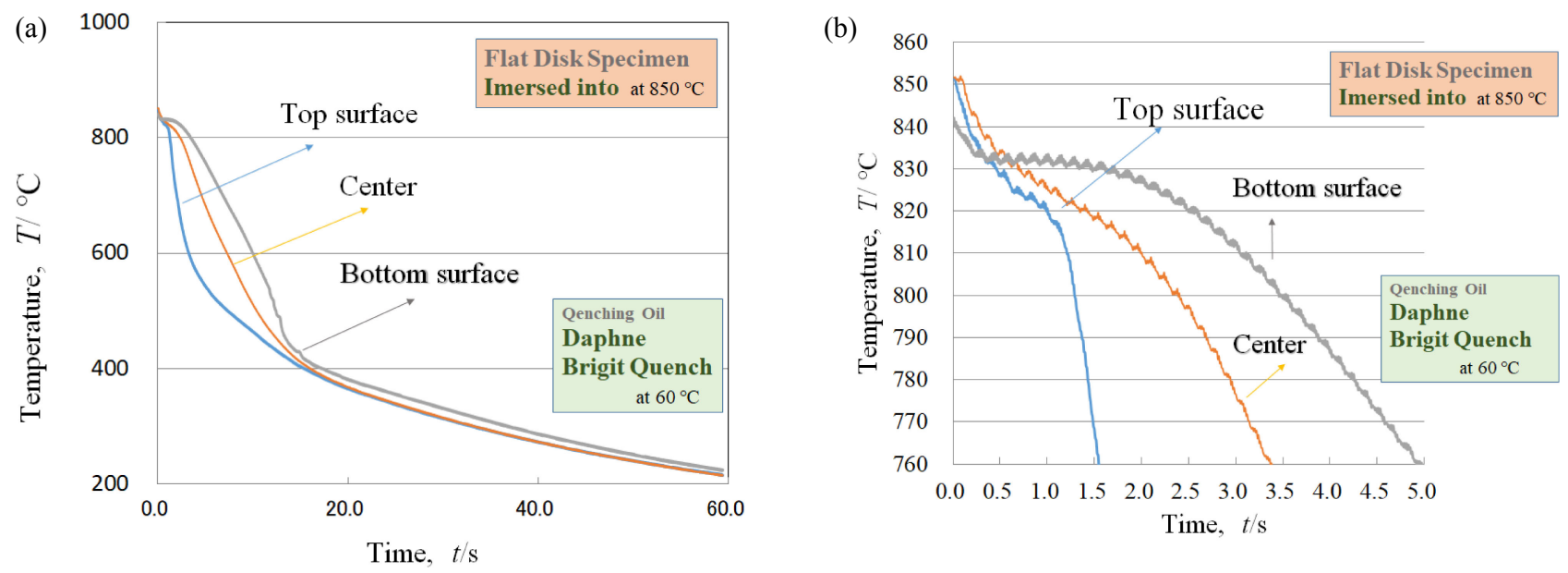

Fig. 5 Cooling curves on center, top and bottom surfaces of disk. (a) Cooling curves 0-60 s. (b) Cooling curves 0-5 s.

Thus, all of time steps (60-200) were identified, and heat transfer coefficient curves were also completed.

Now, this time, in order to make the calculated values coincide with measured values and bring the difference between them to the target such as $\pm \delta_{\beta}$ or less, $\pm \delta T_{1}$ or less, or $\pm \delta T_{1}$ or less, a method of setting the change amount to be smaller each time and ending the wandering was adopted, as shown in Fig. 4, the $T_{1}$ is the top surface temperature and $T_{2}$ is the bottom surface temperature. This time $\delta_{\beta}$ was set to $1.00 \times 10^{-8}$, and $\delta T_{1}$ was $0.1013^{\circ} \mathrm{C}$.

\section{Results and Discussion}

\subsection{Cooling curves and visualization of phenomenon}

The measured cooling curves are shown in Figs. 5, 6 and 7 show the observation results of the high-speed camera capturing the phenomenon that occurred around the disk.

\subsubsection{Results of cooling curves}

On the top surface of the disk, the first boiling stage of $0.23 \mathrm{~s}$ up to $836.6^{\circ} \mathrm{C}$ was observed immediately after the start of cooling, then a cooling curve was obtained in which the film boiling region at once until $1.11 \mathrm{~s}$ up to $816.0^{\circ} \mathrm{C}$. This vapor film stage was present for $0.88 \mathrm{~s}$ seconds, after which the vapor film collapsed and the temperature at that time was determined as the characteristic temperature. On the other hand, no vapor film was formed on the bottom surfaces, too, in the first boiling phase, the temperature and time of which was observed to about $833.7^{\circ} \mathrm{C}$ in $0.23 \mathrm{~s}$. Slow cooling which was covered over a stable vapor film for more than $10 \mathrm{~s}$ after that was observed in the bottom surface. 

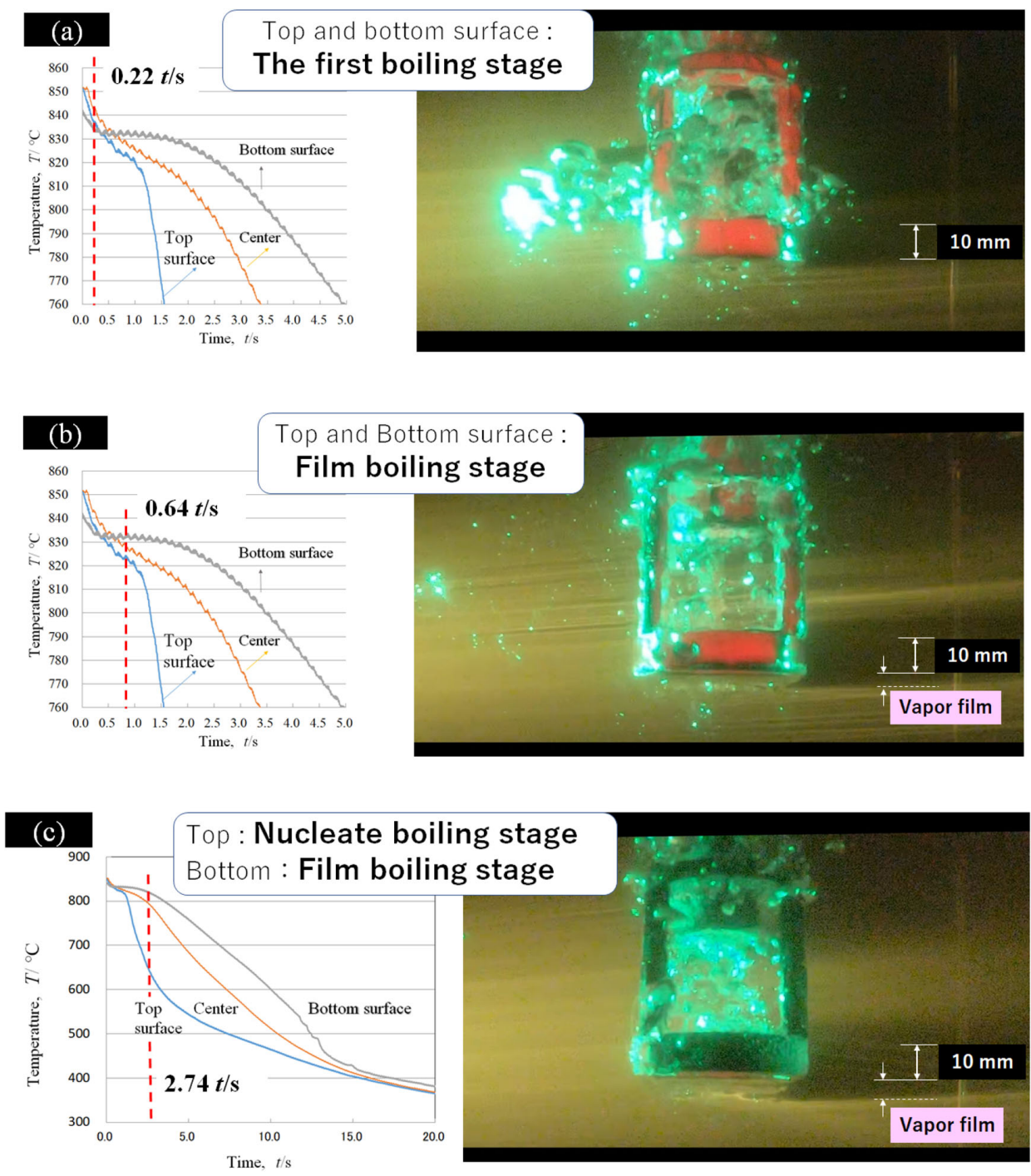

Fig. 6 Cooling curves and visualizing image (240 fps) between $0-2.75 \mathrm{~s}$.

The bottom surface seemed to remain stable boiling film under the surface until $12 \mathrm{~s}$ at $525^{\circ} \mathrm{C}$. Then the bottom surface shifted to the nucleate boiling stage. The bottom surface was then cooled with a curve parallel to the top surface, and both surfaces migrated to convection cooling from around 450 to $400^{\circ} \mathrm{C}$.

\subsubsection{Relationship between cooling curve and visual- ization result}

In the first boiling stage up to $0.23 \mathrm{~s}$, vapor bubbles were explosively generated, and stable vapor film formation was not observed even on the bottom surface where the vapor usually remains.

However, at $0.64 \mathrm{~s}$ after the disk was immersed into the coolant, it changed to a stable vapor film and the substance blocking the laser beam was observed as a shadow behind the disk (cannot see the something that where under the bottom surface, but can be observed a shadow of that where behind the specimen), as shown in Fig. 6(b).

When the vapor film was in a state at which the temperature was higher than the boiling point of the liquid, the liquid was vaporized, and fine vapor bubbles generated and floated together without the coalesce.

From the fact that the laser beam was cut off, it was speculated that the fine vapor particles did not transmit the laser beam, and the size was larger than the wavelength of the laser beam of $532 \mathrm{~nm}$.

Individual fine vapor bubbles were observed moving actively and move freely off the bottom surface, as shown in Figs. 6(b), (c), and Figs. 7(a)-(c).

After about $40 \mathrm{~s}$, when the bottom surface is cooled to $300^{\circ} \mathrm{C}$, the fine vapor bubbles disappeared, and as shown in Fig. 7(d), large bubbles remain with a thick gas-liquid interface close to about $1 \mathrm{~mm}$ with a diameter of about $10 \mathrm{~mm}$ or more. Figure $7(\mathrm{~d})$ is a photograph of the bottom surface. The gas-liquid interface rotates clockwise from the bottom at a speed of about 1 revolution/s without leaving the bottom surface. However, nucleate boiling on the top surface started after $1.11 \mathrm{~s}$ at a characteristic temperature of $816^{\circ} \mathrm{C}$.

It was extremely intense up to around $600^{\circ} \mathrm{C}$, and a large amount of vapor bubbles with a diameter from $1 \mathrm{~mm}$ or less to $10 \mathrm{~mm}$ were generated from the top surface and floated upward.

The number of vapor bubble decreases to $1 / 2$ or less up to near $550^{\circ} \mathrm{C}, 1 / 100$ at $500^{\circ} \mathrm{C}$, and 0 at $450^{\circ} \mathrm{C}$, as shown in Figs. 4(c) and 5(a)-(c). 

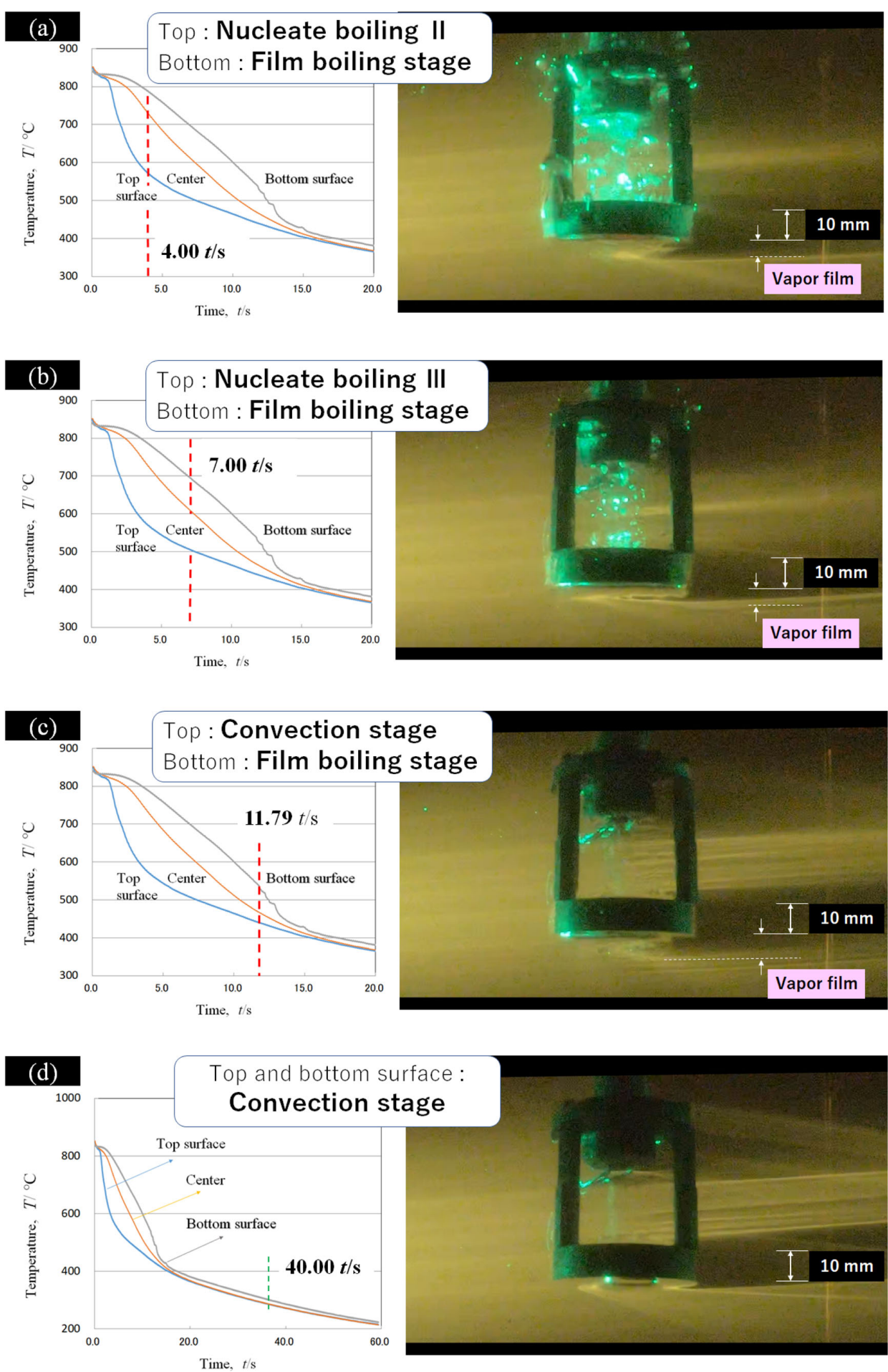

Fig. 7 Cooling curves and visualizing image (240 fps) between 4-40 s.

\subsection{Heat transfer coefficient}

From the cooling curves data in Fig. 3, the temperaturedependent heat transfer coefficient of two parallel planes was identified using the method in section 2-3, the relationship with temperature is shown in Fig. 8(a) and the time course is shown in Fig. 8(b). Both the top and bottom surfaces underwent a film boiling stage where the bottom surface drops to $270 \mathrm{~W} /\left(\mathrm{m}^{2} \cdot \mathrm{K}\right)$ after the first boiling stage, then nucleate boiling cooled the surface at about $1457 \mathrm{~W} /\left(\mathrm{m}^{2} \cdot \mathrm{K}\right)$ from around $491^{\circ} \mathrm{C}$ and changed from the $375^{\circ} \mathrm{C}$ at 346 $\mathrm{W} /\left(\mathrm{m}^{2} \cdot \mathrm{K}\right)$ to convection cooling. The top surface dropped to
$384 \mathrm{~W} /\left(\mathrm{m}^{2} \cdot \mathrm{K}\right)$ after the first boiling stage, and nucleate boiling cooled the surface at about $2310 \mathrm{~W} /\left(\mathrm{m}^{2} \cdot \mathrm{K}\right)$ from around $591^{\circ} \mathrm{C}$ and changed from $359^{\circ} \mathrm{C}$ at $582 \mathrm{~W} /\left(\mathrm{m}^{2} \cdot \mathrm{K}\right)$ to convection cooling, as shown in Fig. 8(a).

The heat transfer coefficient on the top surface increased from $384 \mathrm{~W} /\left(\mathrm{m}^{2} \cdot \mathrm{K}\right)$ in the first boiling stage and reached the $2000 \mathrm{~W} /\left(\mathrm{m}^{2} \cdot \mathrm{K}\right)$ in $2.16 \mathrm{~s}$. It reached a maximum of 2310 $\mathrm{W} /\left(\mathrm{m}^{2} \cdot \mathrm{K}\right)$ at $3.41 \mathrm{~s}$ and then remained at $1870 \mathrm{~W} /\left(\mathrm{m}^{2} \cdot \mathrm{K}\right)$ or more until around $11 \mathrm{~s}$. Heat transfer coefficient of the bottom surface increased from $212 \mathrm{~W} /\left(\mathrm{m}^{2} \cdot \mathrm{K}\right)$ in the first boiling stage and reached a stable film boiling stage for about $10 \mathrm{~s}$. It 
(a)

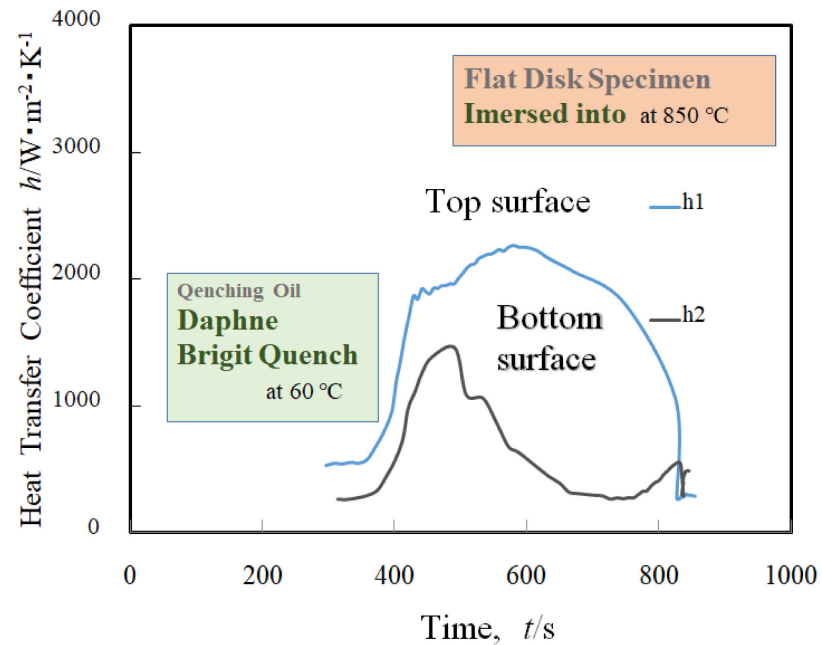

(b)

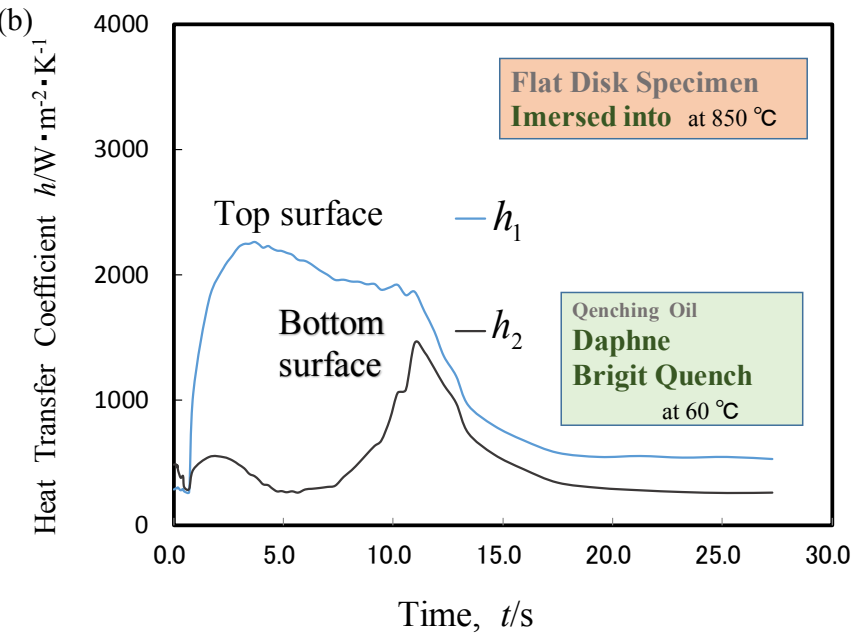

Fig. 8 Identified heat transfer coefficient $h_{1}(T)$ and $h_{2}(T)$ from the cooling curves as shown in Fig. 5. (a) Heat transfer coefficient $h_{1}(T)$ and $h_{2}(T)$ for temperature. (b) Heat transfer coefficient $h_{1}(T)$ and $h_{2}(T)$ for time.

(a)

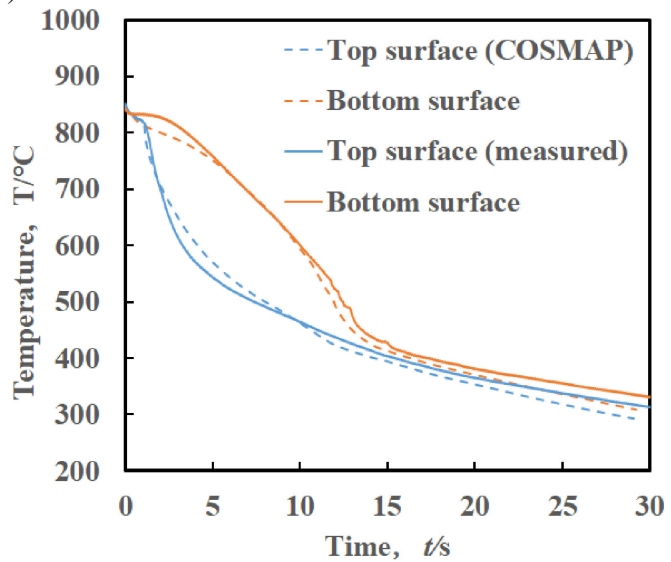

(b)

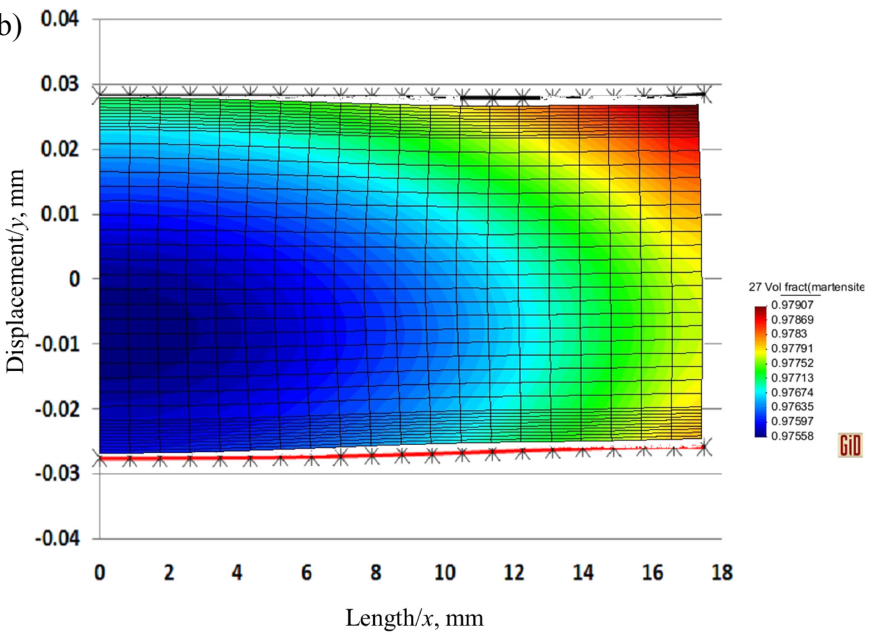

Fig. 9 Comparison of simulation results and measured data. (a) Cooling curves of SUS 304 steel. (b) Quenching Distortion of SCM420 steel.

then reached $1457 \mathrm{~W} /\left(\mathrm{m}^{2} \cdot \mathrm{K}\right)$. Both sides then shifted to a convection stage at $1000 \mathrm{~W} /\left(\mathrm{m}^{2} \cdot \mathrm{K}\right)$ or less, as shown in Fig. 8(b).

\subsection{Simulation results}

The above heat transfer coefficients were input into the CAE heat treatment simulation code COSMAP to simulate the quenching process of the SUS304 disc and SCM420 steels. The simulation results and the measured values of the cooling curves for SUS304 are shown in Fig. 9(a), showing that simulation result was in good agreement with the measured values. Since deformation and strain prediction after quenching for SCM420 is important for quality control, we compared the simulation results with measuring results using deformation after quenching, clearly showing that they are in good agreement.

\section{Conclusion}

The following conclusions were obtained from this study;

(1) To observe the temperature change, a method was used in which the wire was pulled out of the sheath and the welding contact was fixed to the tip of the oblique hole. On the other hand, surface temperature is accurately measured using two parallel thermocouples. An experiment was conducted to determine the boiling behavior of the sample. Using this method, rapid temperature changes during the first boiling stage during the quenching were measured.

(2) Prior to formation of vapor film, a quenching region at the first boiling stage was confirmed.

(3) When the temperature of top surface cooled from $850^{\circ} \mathrm{C}$ to $836^{\circ} \mathrm{C}$ for $0.23 \mathrm{~s}$, the first boiling stage of oil was observed. Thereafter, the boiling stage of film was observed up to $816^{\circ} \mathrm{C}$.

(4) The observed results from the high-speed camera using the laser beam sheet corresponded well to the observed results from the above-mentioned cooling curves, and through both, the phenomenon was accurately observed and the substance could be understood more.

(5) Using the analytical method as the heat conduction equation, temperature-dependent heat transfer coefficients were identified for the top and bottom surfaces as the boundary condition. 
(6) As a result, the cooling curves of SUS304 steel were obtained by heat treatment simulation code COSMAP, inputting the boundary conditions of 2D thermal conductive analysis about SUS304 steel. And these are consistent with that which was obtained by the actual measurements. Namely, the experiments, identification analysis and validity were verified.

(7) It is also able to predict the heat treatment distortion of SCM420 steel whose top and bottom surfaces were carried out the different cooling process. It is observed that predicted values are consistent with the measurement values.

\section{REFERENCES}

1) V.K. Dhir: Proceedings of the Third Microgravity Fluid Physics Conference, NASA CP-3338, (1996) pp. 153-158.

2) J. Jan and D. Scott MacKenzie: Thermal Processing in Motion 2018Conference Proceedings, Spartanburg, South Carolina, USA, (ASM International, Almere, 2018) pp. 112-123.

3) M. Tagaya and I. Tamura: J. Jpn. Inst. Metals B 15 (1951) 589-594.

4) T. Inoue and Z.G. Wang: Mater. Sci. Technol. 1 (1985) 845-850.

5) T. Inoue, D.Y. Ju and K. Arimoto: Proc. 1st Int. Conf. on Quenching and the Control of Distortion, (ASM International, Almere, 1992) pp. 205-212.

6) R. Mukai and D.Y. Ju: J. Phys. IV 120 (2004) 489-497 (proceedings)

7) D.Y. Ju, W.M. Zhang and Y. Zhang: Mater. Sci. Eng. A 438-440 (2006) 246-250.

8) Y. Watanabe, D.-Y. Ju, H. Shichino, K. Okamura, M. Narazaki, H. Kanamori, K. Ichitani and T. Inoue: Solid State Phenomena 118 (2006) 349-354.

9) T. Inoue, Y. Watanabe, K. Okamura, M. Narazaki, H. Shichino, D.-Y. Ju, H. Kanamori and K. Ichitani: Key Eng. Mater. 340-341 (2007) 1061-1066.

10) T. Inoue, Y. Watanabe, K. Okamura, M. Narazaki, H. Shichino, D.-Y. $\mathrm{Ju}, \mathrm{H}$. Kanaraori and K. Ichitani: Transaction of Materials and Heat Treatment, Proceedings of the 14th of the Congress, Vol. 25, No. 5, (2004) pp. 28-34.

11) H. Kanamori, E. Nakamura, H. Uchida, S. Koyama and T. Inoue: Netsushori 36(6) (1996) 390-395.

12) M. Tagaya and I. Tamura: J. Jpn. Inst. Metals B 15 (1951) 538-541.

13) M. Mitsutsuka and K. Fukuda: Tetsu-to-Hagané 60, 2079-2084 (1974)

14) JIS K 2242 method A: Japan Industrial Standard, Measurement of surface temperature, (2012).

15) H. Hu, C. Xu, Y. Zhao, K.J. Ziegler and J.N. Chung: Sci. Rep. 7 (2017) 6117.

16) M. Necati Özıș1k: Heat Conduction, Second Edition, (John Wiley \& Sons, Inc., Hoboken, 1993) pp. 1-47. 